\title{
Rules for diagnosis of arterioventricular discordances and spatial identification of ventricles Crossed great arteries and transposition of the great arteries
}

\author{
Maria V. de la Cruz, José R. Berrazueta, Manuel Arteaga, Fause Attie, and Jorge Soni \\ From the Department of Embryology, Instituto Nacional de Cardiología, México 7, D.F. México
}

Rules are presented for the diagnosis of arterioventricular discordances and the spatial position of the ventricles in these cardiopathies by means of angiocardiography and the position of cardiac catheters. Because these rules are based on previous anatomo-embryological findings, the normal development of the conus and the truncus is briefly analysed. The probable morphogenesis of this group of truncoconal cardiopathies is discussed.

The fundamental process required to establish the diagnosis of these cardiopathies is as follows:

1) The truncoconal morphology is identified in the lateral projection. a) The anterior position of the pulmonary artery and its infundibulum with respect to the aorta and its infundibulum is characteristic of crossed great arteries with arterioventricular concordance or discordance. b) The anterior position of the aorta and its infundibulum with respect to the pulmonary artery and its infundibulum is characteristic of transposition of the great arteries with arterioventricular concordance or discordance.

2) Once the truncoconal morphology is identified, the use of the anteroposterior projection allows the establishment of the differential diagncsis between arterioventricular concordances and discordances, and of the spatial location of the ventricles in these entities. a) An anterior pulmonary artery directed from right to left, emerging from an infundibulum placed on the left side (anatomically right ventricle on the left) or an anterior pulmonary artery directed from left to right, arising from an infundibulum located to the right (anatomically right ventricular placed on the right), is the specific image of discordant crossed great arteries. b) An anterior pulmonary artery directed from right to left emerging from an infundibulum placed on the right side (anatomically right ventricle on the right side) or the anterior pulmonary artery directed from left to right arising from a left-sided infundibulum (anatomically right ventricle placed on the left side) is characteristic of concordant crossed great arteries. c) An anterior aorta placed to the right of the pulmonary artery and emerging from a left-sided infundibulum (anatomically right ventricle placed on the left side) or an anterior aorta placed to the left of the pulmonary artery and arising from an infundibulum placed on the right side (anatomically right ventricle placed on the right) is characteristic of discordant transposition of the great arteries. d) An anterior aorta placed to the right of the pulmonary artery emerging from a right-sided infundibulum (anatomically right ventricle placed on the right) or an anterior aorta placed to the left of the pulmonary artery arising from an infundibulum placed on the left (anatomically right ventricle placed on the left) is the specific picture of concordant transposition of the great arteries.

Reference is made to rules for the diagnosis of visceral situs and atrioventricular relations in order to determine whether the arterioventricular discordance corresponds to the variety with atrioventricular discordance or concordance.

Angiocardiographic postmortem studies of arterioventricular discordances and concordances are presented in support of the above considerations.

Arterioventricular discordances seem to have become more numerous as one reviews the published reports (de la Cruz et al., 1974; Van Praagh et al.,

Received 2 June 1975.
1975; Kirklin et al., 1973; Shaffer et al., 1967; Danielson et al., 1972; Raghib, Anderson, and Edwards, 1966). Nevertheless they are still a small group among all the truncoconal cardiopathies. The purpose of this paper is to establish rules 
for the diagnosis of the different varieties of arterioventricular discordances and the spatial identification of the ventricles in this group of truncoconal malformations based on a previous paper (de la Cruz et al., 1974) which was concerned with their anatomo-embryological interpretation and classification. A brief account of the rules for the diagnosis of the visceral situs and of the atrioventricular relations is also given, since this is indispensable in diagnosing precisely the variety of arterioventricular discordance (de la Cruz et al., 1974). Reference is also made to the anatomical features and rules for the diagnosis of arterioventricular concordances (de la Cruz and Nadal-Ginard, 1972) in order to establish the differential diagnosis between this entity and arterioventricular discordances.

Postmortem studies are presented using contrast medium in the ventricles and the great arteries in specimens with crossed great arteries, and with transposition of the great arteries with arterioventricular discordance and with arterioventricular concordance.

\section{Embryological considerations}

The rules for the identification of the spatial position of the ventricles in patients with arterioventricular concordance (de la Cruz and Nadal-

FIG. 1 Microdissections of chick embryo hearts at stage 25 of Hamburger and Hamilton ( 4.5 to 5 days) which shows relations of both coni with primordium of the trabeculated region of the right ventricle and spatial orientation of truncoconal ridges. (A) Anterior and right wall of anterior conus and part of wall of primordium of trabeculated region of the right ventricle $(R V)$ have been removed in order to show dextrodorsal conus ridge (D-DCR) and sinistroventral conus ridge ( $S-V C R$ ) which separate anterior conus from posterior conus. Note posterior wall of posterior conus or conoventricular flange (C-VF) forming one edge of primary interventricular foramen (PIF). (B) Cross-section at level of both coni with two hairs, one is introduced in anterior conus (AC) and other in posterior conus (PC). Note spatial relation of both coni to each other and with respect to primordium of trabeculated region of right ventricle $(R V)$. Both atria are continuous with left ventricle (LV). (C) Part of wall of truncus and of conus have been removed in order to show that dextrodorsal conus ridge (D-DCR) is continuous with sinistroventral truncus ridge $(S-V T R)(\times 36)$.

The white arrows indicate the truncoconal junction.

Key to abbreviations: $R A$, Right atrium. $L A$, Left atrium.
Ginard, 1972) or discordance with crossed great arteries or with transposition of the great arteries are based on the anatomical relation of the great arteries with the infundibulum of the anatomically right ventricle. This arterio-infundibular relation has been established on the basis of embryological concepts. Therefore, it is necessary to discuss briefly the normal development of the conus and the truncus and also the probable morphogenesis of transposition of the great arteries for which differing
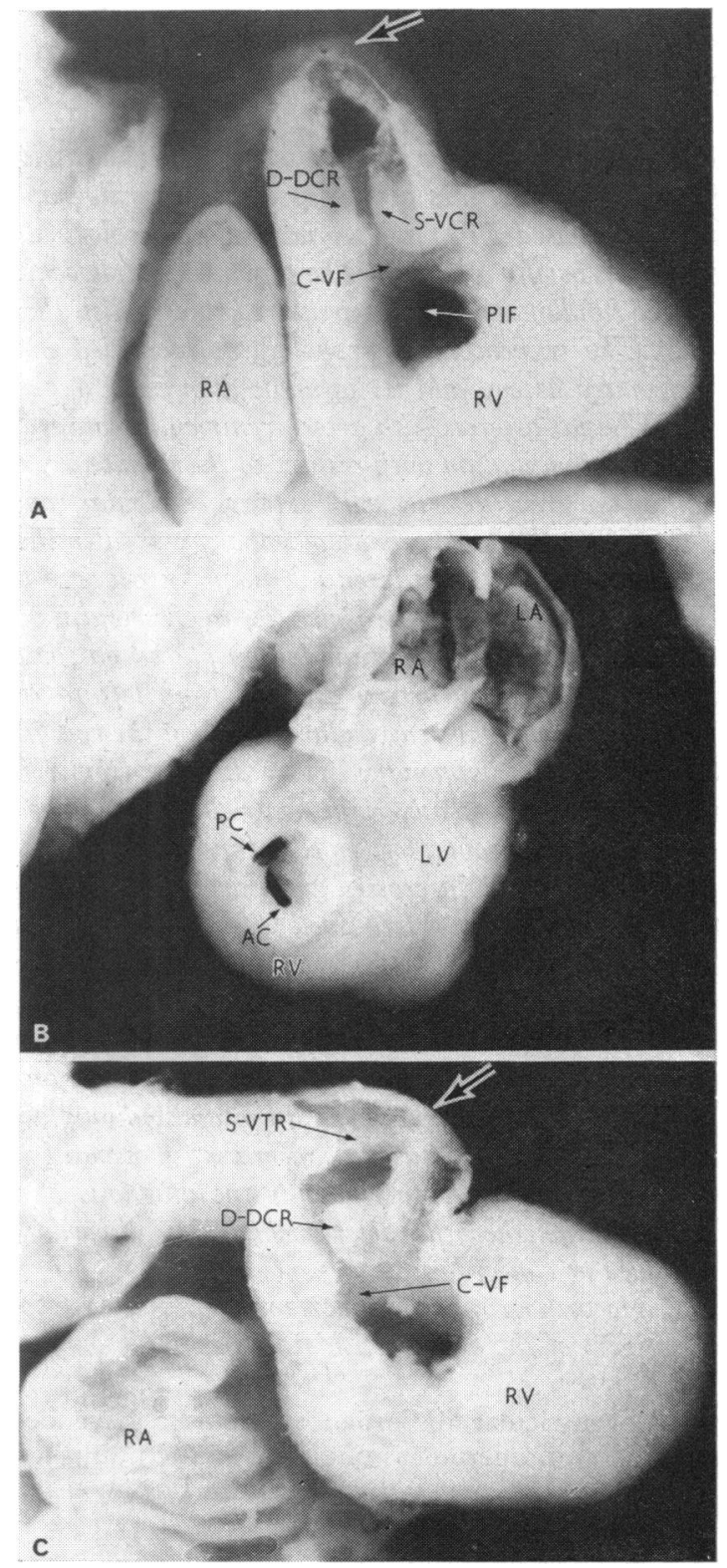
hypotheses have been presented (Van Praagh and Van Praagh, 1966; de la Cruz and da Rocha, 1956; Netter and Van Mierop, 1969).

The conus is the segment of the primary heart tube $^{1}$ situated between the truncus distally and the primordium of the trabeculated region of the right ventricle proximally (De Vries and Saunders, 1962). This portion of the primary heart tube has been variously designated: De Vries and Saunders (1962) call it 'infundibulum'; Kramer (1942), and Goor, Dische, and Lillehei (1972) call it 'conus'; Van Mierop et al. (1962) call it 'conus cordis', and Van Praagh and Van Praagh (1966) 'distal conus'.

De Vries and Saunders (1962), using descriptive embryology, established the early anatomical characteristics which permit the recognition of the conus and indicated that this structure appeared in Horizon XI of Streeter. The most relevant characteristics are its smooth walls which differ from those of the primordium of the trabeculated region of the right ventricle, with which it becomes continuous, and the presence of two conal ridges: a dextrodorsal and a sinistroventral one (Fig. 1A). These conal ridges divide the conus in an anterior and right-sided conus and a posterior and left-sided conus (Fig. 1A and B). Both coni are situated above the primordium of the trabeculated region of the anatomically right ventricle (Fig. $1 \mathrm{~A}$ and $\mathrm{B}$ ) (De Vries and Saunders, 1962; Van Mierop et al., 1962; Kramer, 1942; de la Cruz, Muñoz-Armas, and Mũnoz-Castellanos, 1972). This is so, from the time of appearance of both coni in the Horizon XI of Streeter up to Horizon XVI of Streeter when the posterior conus is incorporated in the left ventricle (Van Mierop et al., 1962) by an unknown developmental process. This has been shown by Gessner and Van Mierop (1970) using experimental embryological techniques in a beautiful experiment in which by preventing the incorporation of the posterior conus into the left ventricle both coni remained on the anatomically right ventricle, one of them anterior and right-sided and the other one, posterior and left-sided. When the posterior conus is incorporated in the left ventricle, the posterior wall of this conus (conoventricular flange) constituting one of the rims of the primary interventricular foramen (Fig. 1A and C) is reshaped and forms the infundibulum of the anatomically left ventricle, therefore establishing the fibrous continuity of this conus with the mitral valve. This is the process whereby the left ventricle acquires its outflow tract (Van Mierop et al., 1962; de la Cruz et al.,

1Streeter (1945) considers the primary heart tube as that portion of the developing heart between the atrioventricular junction and the arterial arches.
1972). The anterior conus remains in the anatomically right ventricle forming the infundibulum of this chamber (Van Mierop et al., 1962; Netter and Van Mierop, 1969; Van Mierop, 1974; de la Cruz et al., 1972). The posterior wall of the anterior conus, formed by the fused conus ridges, constitutes the horizontal portion of the crista supraventricularis and part of the definitive interventricular septum (Netter and Van Mierop, 1969; Van Mierop, 1974). The anatomically right ventricle is comprised, from the embryological point of view, of the anterior conus and the primordium of the trabeculated portion of the right ventricle. These structures give the right ventricle its distinctive features in the mature heart.

De Vries and Saunders (1962) describe the truncus as the distal segment of the primary heart tube, which is situated in the sagittal plane while the other segments are situated in the frontal plane. The truncus at its proximal end is continuous with the conus by means of an angular junction (Fig. 1A and $C$ ) where the semilunar valves of the great arteries will develop (De Vries and Saunders, 1962) and at its distal end with the aortic sac, by which it connects with the aortic arches. The truncus has two ridges: one is dextrodorsal (Kramer, 1942) or dextroinferior (De Vries and Saunders, 1962; Netter and Van Mierop, 1969) and the other sinistroventral (Kramer, 1942) or sinistrosuperior (De Vries and Saunders, 1962; Netter and Van Mierop, 1969). Kramer (1942). De Vries and Saunders (1962); Netter and Van Mierop (1969), and de la Cruz et al. (1972) have shown that the dextrodorsal conus ridge is continuous with the sinistroventral or sinistrosuperior truncus ridge, while the sinistroventral conus ridge is continuous with the dextrodorsal or dextroinferior truncus ridge. In this way the truncoconal ridges develop in a spiral fashion and when they fuse they constitute an equally spiral septum with a rotation of approximately 180 degrees in a clockwise direction if seen from the distal end (Fig. 1C).

The 4th aortic arch (horizontal portion of the aortic arch) joins the anterior and right portion of the distal end of the truncus, and the 6th aortic arch (branches of the pulmonary artery) joins its posterior and left portion. The development of the truncoconal septum in a spiral fashion causes the left and posterior 6th aortic arch (branches of the pulmonary artery) to communicate with the anterior conus (infundibulum of the anatomically right ventricle), while the anterior and right 4th aortic arch (horizontal portion of the aortic arch) communicates with the posterior conus (infundibulum of the anatomically left ventricle) (Fig. 2A). Thus, when the septation of the truncus is com- 
pleted, it has been divided into two segments: one between the 6th aortic arch and the anterior conus, forming in the mature heart, the trunk of the pulmonary artery which crosses the aorta ventrally. The other segment is situated between the 4th aortic arch and the posterior conus; it gives origin to the ascending portion of the aorta of the mature heart which crosses the pulmonary arterial trunk posteriorly. This is the normal morphology of crossed great arteries (Fig. 2A).

The sigmoid aortic and pulmonary valve cusps originate in the wall of the truncus at the site of the conotruncal junction (De Vries and Saunders, 1962; Netter and Van Mierop, 1969). The two

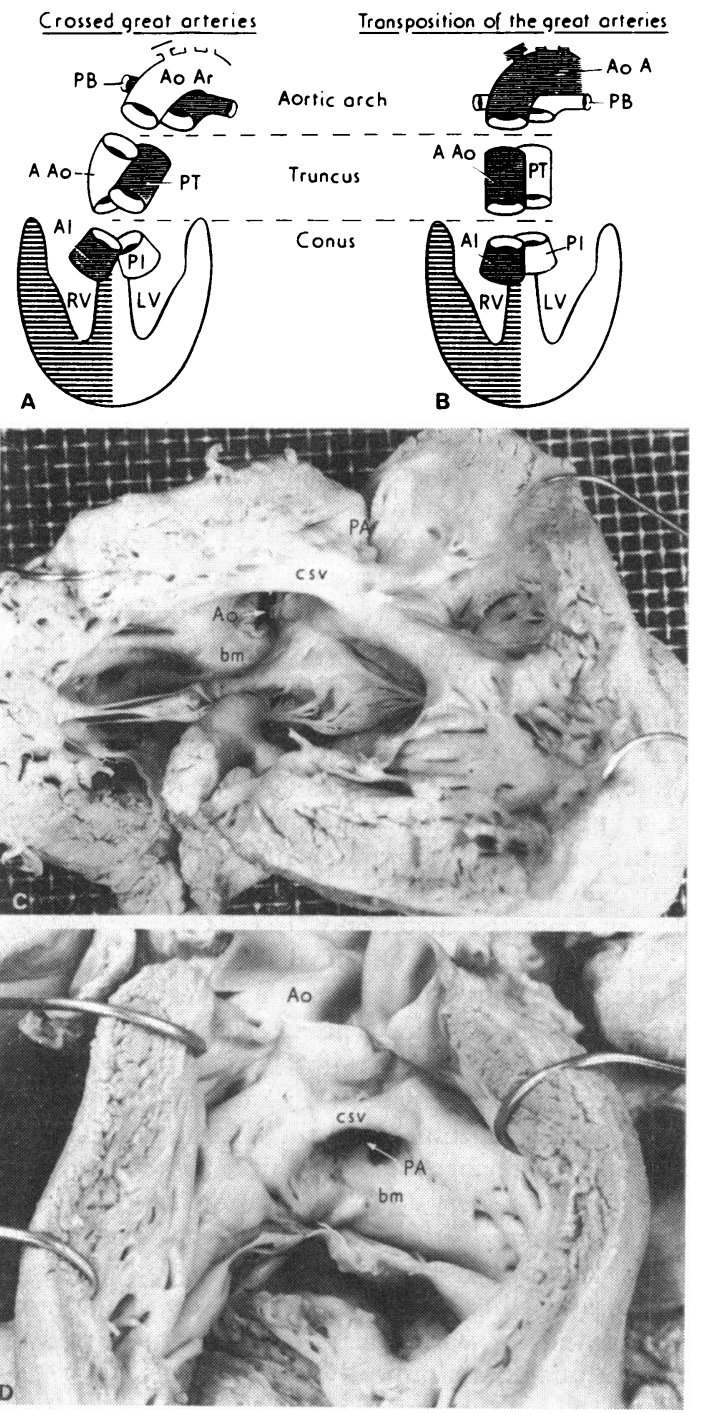

coronary sigmoid valve cusps of the aorta and the two posterior sigmoid valve cusps of the pulmonary artery originate from the ridges of the truncus while the non-coronary sigmoid valve cusp of the aorta and the anterior cusp of the pulmonary artery originate from the intercalar cushions.

Evidence obtained with techniques for descriptive and experimental embryology shows that the normal rotation of the truncoconal septum determines the normal morphology of crossed great arteries. These facts allow us to advance a hypothesis (de la Cruz and da Rocha, 1956), that the lack of rotation of the truncus septum will cause the branches of the pulmonary artery (6th aortic arch) which are posterior and left-sided to communicate by way of the pulmonary arterial trunk with the posterior conus. On the other hand, the horizontal portion of the aortic arch (4th aortic arch) which is anterior and right-sided will communicate with the anterior conus (infundibulum of the anatomically right ventricle) by way of the ascending portion of the aorta. This will cause the ascending portion of the aorta to be placed in a ventral position with respect to the trunk of the pulmonary artery (Fig. 2B). This anatomical arrangement constitutes our concept of transposition of the great arteries; it is for this reason that we do not include truncoconal morphologies with a posterior aorta or the side-by-side great arteries under this designation.

Transposition of the great arteries has two varieties. The most frequent one is seen with arterio-

FIG. 2 Relations of both great arteries with their infundibula in crossed great arteries and in transposition of great arteries. (A) Diagrammatic representation of relations of trunk of pulmonary artery (PT) and of ascending portion of aorta (AAo) in crossed great arteries. (B) Diagram of relations of ascending portion of aorta (AAo) with trunk of pulmonary artery (PT) in transposition of great arteries. (C) Specimen with crossed great arteries. Observe posterior aorta (Ao) with greater subaortic muscular mass (bm) with respect to pulmonary artery $(P A)$ which has smaller muscular subpulmonary mass $(C S V)$. (D) Anatomical specimen with transposition of great arteries. Observe posterior pulmonary artery (PA) with greater subpulmonary muscular mass (bm) than anterior aorta (Ao) which has smaller subaortic muscular mass (CSV).

Key to abbreviations: bm, Bulbar muscle (posterior wall of posterior conus). CSV, Horizontal portion of crista supraventricularis (posterior wall of anterior conus). AoAr, aortic arch. PB, pulmonary branches. $A I$, anterior infundibulum. PI, posterior infundibulum. $R V$, right ventricle. $L V$, left ventricle. 


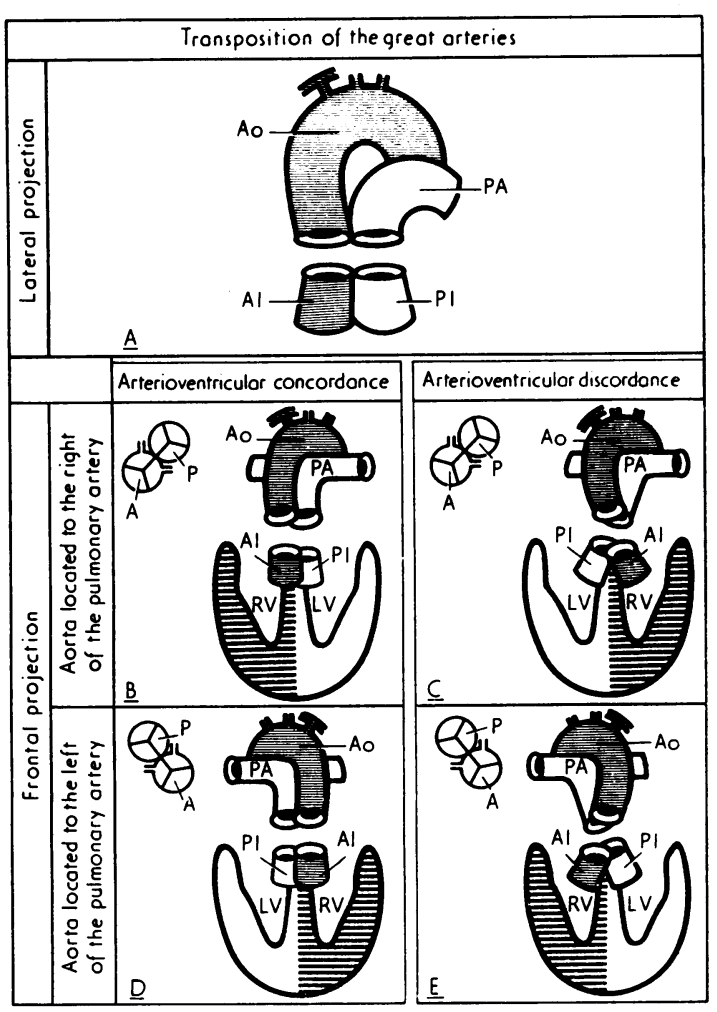

FIG. 3 Representative diagrams of relations of great arteries with their infundibula and with spatial location of ventricles in transposition of great arteries. (A) Diagram of lateral view in order to show anterior position of aorta and its infundibulum with respect to pulmonary artery and its infundibulum, which is general characteristic of transposition of great arteries. ( $B, C, D$, and $E$ ) Frontal view depicting relation between ascending portion of aortic arch and anterior infundibulum which permits identification of spatial position of anatomically right ventricle. Diagram ( $B$ and $D$ ) shows that anterior aorta and its infundibulum placed on same side and parallel to pulmonary arterial trunk and its infundibulum are features which characterize concordant transposition of great arteries, while in $C$ and $E$ anterior aorta arising from an infundibulum placed on opposite side is distinctive feature of discordant transpositions of great arteries.

Key to abbreviations: Ao, aorta; $P A$, pulmonary artery; $A I$, anterior infundibulum; PI, posterior infundibulum; $R V$, right ventricle; $L V$, left ventricle; $A$, aortic sigmoid valve cusps; $P$, pulmonary sigmoid valve cusps. ventricular concordance and the least common one with arterioventricular discordance (de la Cruz et al., 1974). Both originate on the basis of a nonrotated septum. In the variety with arterioventricular concordance the orientation of the truncus septum corresponds to the type of bulboventricular loop present, which determines the spatial position of the ventricles (de la Cruz et al., 1974). Thus, a non-rotated truncus septum directed from right to left in a dorsoventral sense with a convex rightsided bulboventricular loop produces the anatomical picture characterized by an anterior and right-sided aorta with respect to the pulmonary arterial trunk and emerging from the anterior infundibulum on the right side (anatomically right ventricle on the right) (transposition of the great arteries with arterioventricular concordance) (Fig. $3 \mathrm{~B}, 4 \mathrm{C}$ and $5 \mathrm{C}$ ).

In the variety with arterioventricular discordance the orientation of the truncus septum does not correspond to the type of accompanying bulboventricular loop (de la Cruz et al., 1974). Thus a nonrotated truncus septum directed from right to left in a dorsoventral sense, with a convex bulboventricular loop to the left, determines the anatomical picture characterized by an anterior and right-sided aorta with respect to the pulmonary artery and emerging from the anterior infundibulum situated on the left (anatomically right ventricle on the left side) (transposition of the great arteries with arterioventricular discordance) (Fig. 3C, 4D and 5D).

The great arteries and their valves originate from the truncus so that their reciprocal relation and that of their valvular planes will depend on the orientation of the truncus septum (de la Cruz et al., 1974).

Crossed great arteries present as two varieties: with arterioventricular concordance which is the most frequent and with arterioventricular discordance, which is extremely rare (de la Cruz et al., 1974). Both originate because of a rotated truncus septum, but in the variety with arterioventricular concordance the rotation of the septum corresponds with the type of accompanying bulboventricular loop (de la Cruz et al., 1974). Thus, a truncus septum rotated in a clockwise manner is accompanied by a right-sided convexity of the bulboventricular loop, the anatomical expression of which is an anterior pulmonary artery directed from right to left which emerges from an anterior infundibulum situated on the right (anatomically right ventricle on the right). This occurs in the normal development of the heart (Fig. 6B, 7C, and 8C).

The variety with crossed great arteries and arterioventricular discordance arises because the rotation of the truncus septum does not correspond with the type of bulboventricular loop accompany- 


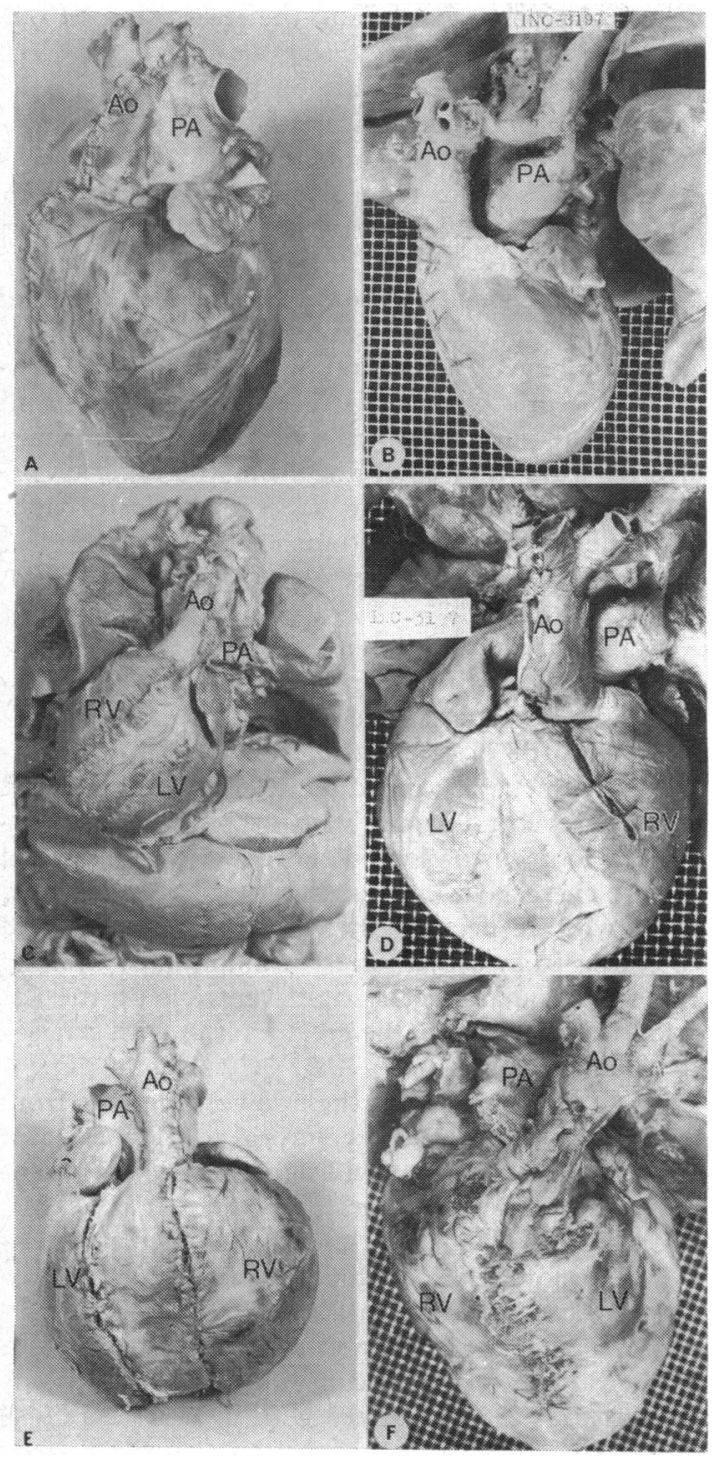

ing it (de la Cruz et al., 1974). Thus, a septum with a clockwise rotation is accompanied by a left-sided convexity of the bulboventricular loop, which is expressed anatomically by an anterior pulmonary artery directed from right to left emerging from an anterior infundibulum located on the left (anatomically right ventricle on the left) (Fig. 6C, 7D and $8 \mathrm{D}$ ).

The great arteries and their valves originate from the truncus (Netter and Van Mierop, 1969) for which reason their mutual relation and that of their valvular planes will depend on the clockwise or
FIG. 4 External view of anatomical specimens with concordant and discordant transposition of great arteries. Angiocardiographic studies of these specimens are seen in Fig. 5. (A) Lateral view of concordant transposition of great arteries and $(B)$ discordant transposition of great arteries. Notice that in both types ascending portion of aortic arch is anterior with respect to trunk of pulmonary artery. (C) Concordant transposition of great arteries with ascending portion of aortic arch located to right of pulmonary arterial trunk. (D) Discordant transposition of great arteries with ascending portion of aortic arch placed on right side of pulmonary arterial trunk. (E) Concordant transposition of great arteries with ascending portion of aortic arch placed on left side of pulmonary arterial trunk. (F) Discordant transposition of great arteries with ascending portion of aortic arch placed on left side of pulmonary arterial trunk.

Key to abbreviations: Ao, aorta; $P A$, pulmonary artery; $R V$, right ventricle; $L V$, left ventricle.

counterclockwise rotation of the truncus septum.

Van Praagh and Van Praagh (1966) indicate that during the normal development when both conuses appear, 'the presumptive aortic conus is right-sided, and the presumptive pulmonary conus is left-sided'. On the basis of this hypothesis he explains 'the normally related great arteries' as originating from an 'expansile growth of the pulmonary conus causing it to protrude anteriorly on the left side, carrying the pulmonary valve anteriorly, superiorly and to the left of the aortic valve, which remains posterior, inferior and relatively right-sided, in contact with the developing mitral valve' (Van Praagh and Van Praagh, 1966).

The findings of De Vries and Saunders (1962), Van Mierop et al. (1962), Netter and Van Mierop (1969), Van Mierop (1974), Kramer (1942), and de la Cruz et al. (1972) indicate that this process does not take place in the normal development of the truncus and of the conus. On the contrary, from the moment both conuses appear, when the conus ridges separating them are still not fused, the pulmonary conus is anterior and right-sided and the aortic conus is posterior and left-sided (Fig. 1A and B). Furthermore the aortic and pulmonary sigmoid valve cusps, which originate from the truncus, appear when the posterior conus has become incorporated into the anatomically left ventricle (de la Cruz et al., 1972). On the other hand, the recent findings of Goor et al. (1972) indicating that both conuses are normally reabsorbed also argue against the hypothesis of a differential growth of the conus. 

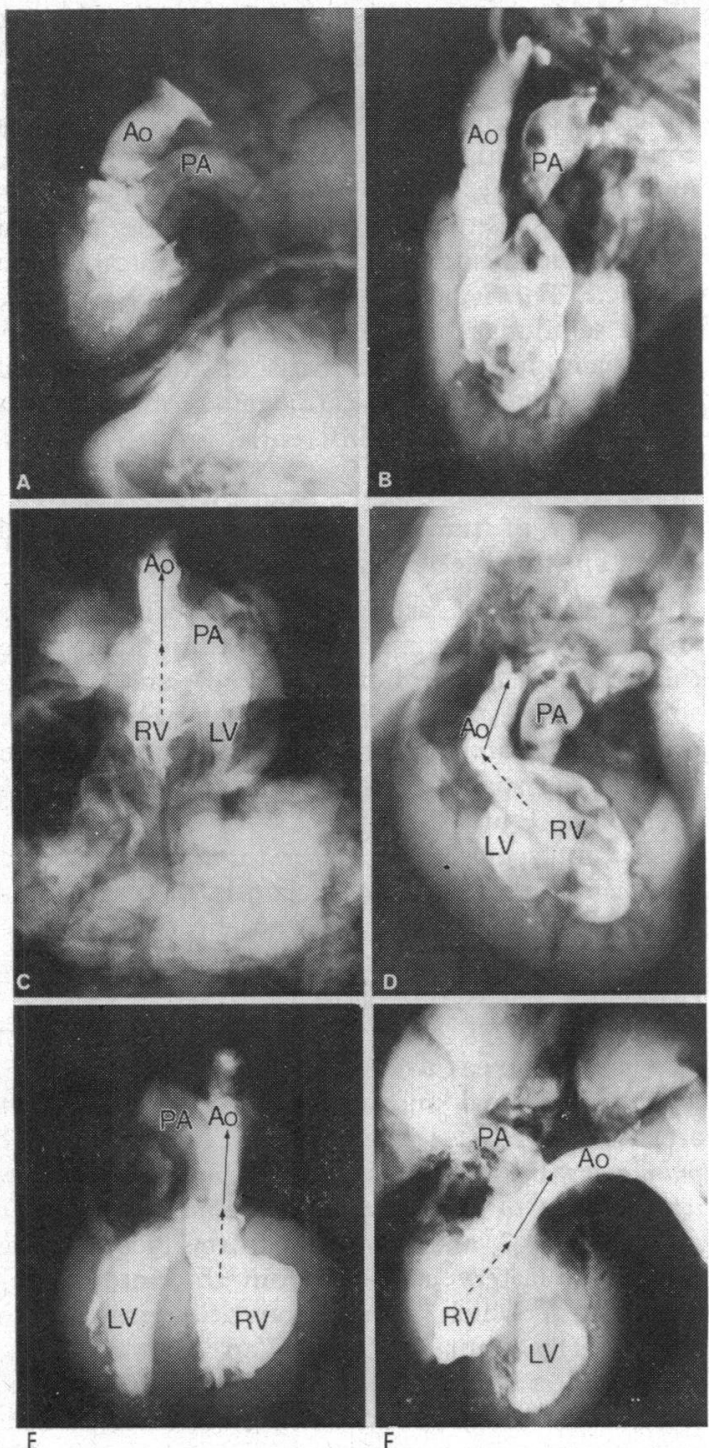

This same hypothesis of a differential growth of the conus explains transposition of the great arteries as follows: 'following d-looping, the presumptive aortic conus is right-sided relative to the presumptive pulmonary conus (normal). Expansile growth of the aortic conus carries the developing aortic valve anteriorly and superiorly on the right side, relative to the pulmonary valve' (Van Praagh and Van Praagh, 1966). This hypothesis lacks solid support because it assumes that there are disturbances of some processes which do not exist in the normal development of the conus and the truncus.
FIG. 5 Angiocardiographic postmortem study of specimens with concordant and discordant transposition of great arteries. Lateral view of $(A)$ concordant transposition of great arteries and $(B)$ discordant transposition of great arteries both showing ascending portion of aortic arch and its infundibulum are anterior with respect to pulmonary artery trunk and its infundibulum which is general characteristic of transposition of great arteries. Frontal view of (C) concordant transposition of great arteries and (D) discordant transposition of great arteries. Notice in (C) that ascending portion of aortic arch is anterior and to right of pulmonary artery trunk and it arises from anterior infundibulum located on right side. This indicates that anatomically right ventricle is on right side, while in (D) ascending portion of aortic arch is also placed anteriorly and to right of pulmonary artery trunk but arises from anterior infundibulum located to left, and this indicates that anatomically right ventricle is placed on left side. Frontal view of $(E)$ concordant transposition of great arteries and $(F)$ discordant transposition of great arteries. Notice in (E) that ascending portion of aortic arch is anterior and placed on left side of pulmonary artery trunk and it arises from anterior infundibulum placed to left, all of which indicates that anatomically right ventricle is placed on left side, while in $(F)$ ascending portion of aortic arch is also placed anteriorly and to left of pulmonary artery trunk but arising from anterior infundibulum placed on right side and this indicates that anatomically right ventricle is placed on right side. The dotted arrow indicates direction of infundibulum of anatomically right ventricle. Full arrow indicates direction of aorta.

Key to abbreviations: Ao, aorta; $P A$, pulmonary artery; $R V$, right ventricle; $L V$, left ventricle.

These concepts go on to indicate that 'more important than the anatomic type of conus that is present (subpulmonary, subaortic, bilateral, absent) is the amount of conal musculature beneath each semilunar valve' (Van Praagh, 1973). These statements are often not supported by anatomical findings, since there are specimens of crossed great arteries with a larger amount of subaortic than of subpulmonary conal musculature (Fig. 2C) and specimens with transposition of the great arteries with a larger amount of subpulmonary conal than subaortic musculature (Fig. 2D).

We interpret the presence of the muscular posterior conus as a result of a developmental disorder in which the posterior wall of this conus instead of differentiating as happens normally into connective tissue, does so into muscular tissue. 


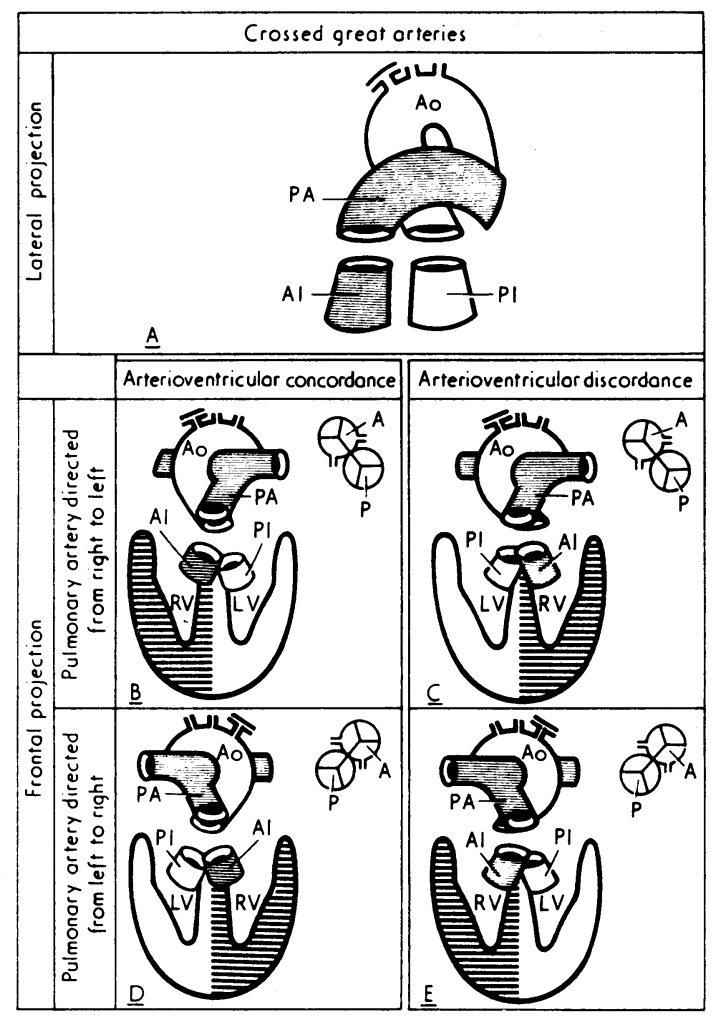

FIG. 6 Representative diagrams of relations of crossed great arteries with their infundibula and with spatial location of ventricles. (A) Diagram of lateral projection in order to show anterior position of pulmonary artery and its infundibulum with respect to aorta and its infundibulum, generally characteristic of crossed great arteries. $(B, C, D$, and $E)$ Frontal projections show that relation between pulmonary artery trunk and anterior infundibulum permits identification of spatial position of the anatornically right ventricle. Diagram ( $B$ and $D$ ) indicates that anteriorly placed pulmonary artery arising from infundibulum located on opposite side is characteristic image of concordant crossed great arteries, while in $(C$ and $E)$ anterior pulmonary artery which arises from infundibulum placed on same side is characteristic feature of discordant crossed great arteries.

Key to abbreviations: Ao, aorta; $P A$, pulmonary artery; $A I$, anterior infundibulum; PI, posterior infundibulum; $R V$, right ventricle; $L V$, left ventricle; $A$, aortic sigmoid valve cusps; $P$, pulmonary sigmoid valve cusps.

Independently of its histological structure, the posterior conus is the posterior infundibulum which is normally incorporated into the anatomically left ventricle. On the other hand, absence of a muscular anterior conus arises because the conus ridges (horizontal portion of the crista supraventricularis), which constitute the posterior wall of the anterior conus, differentiate into connective tissue instead of muscular tissue as it normally does. Therefore, despite its histological constitution the anterior conus is the infundibulum of the anatomically right ventricle. This is how we can interpret the presence of the semilunar atrioventricular fibrous continuity or discontinuity, on the basis of the process of differentiation of the cardiogenic mesenchyma without resorting to a differential growth process.

\section{Diagnosis of truncoconal morphologies and spatial identification of ventricles}

The diagnosis of arterioventricular discordances and concordances is made first of all by identifying the truncoconal morphology (Fig. 3A and 6A) and subsequently establishing the relations between the great arteries and their infundibula, which in turn permits the spatial identification of the ventricles (Fig. $3 \mathrm{~B}$ to $\mathrm{E}$ and $6 \mathrm{~B}$ to $\mathrm{E}$ ).

It is indispensable in order to characterize and establish the differential diagnosis of arterioventricular discordances to refer to the rules for the diagnosis of arterioventricular concordances (de la Cruz and Nadal-Ginard, 1972).

\section{A. Crossed great arteries}

The truncoconal morphology of crossed great arteries, is characterized essentially because the pulmonary artery trunk always has a ventral position with respect to the ascending portion of the aortic arch (Fig. 6, 7, and 8), owing to the fact that the pulmonary artery emerges from the anterior infundibulum which is a region belonging to the anatomically right ventricle (Van Mierop et al., 1962; Netter and Van Mierop, 1969; Van Mierop, 1974). This entity includes two groups: cases with arterioventricular concordance (Fig. 6A, B, D, 7A, $\mathrm{C}, \mathrm{E}$ and $8 \mathrm{~A}, \mathrm{C}, \mathrm{E})$ and cases with arterioventricular discordance (Fig. 6A, C, E, 7B, D, F and 8B, D, F).

1. Concordant crossed great arteries (de la Cruz et al., 1974) (Fig. 6A, B, D, 7A, C, E, and $8 \mathrm{~A}, \mathrm{C}, \mathrm{E})$. Within the group of crossed great arteries the concordant form is the most common. This group has the general features of crossed great arteries, i.e. the pulmonary artery is ventral to the aorta and it arises from the anterior infundibulum (anatomically right ventricle) (Fig. 6A, B, D; 7A, $\mathrm{C}, \mathrm{E}$, and $8 \mathrm{~A}, \mathrm{C}, \mathrm{E})$. The distinctive feature of this entity is that the pulmonary artery and its infundibulum (anterior infundibulum) has the same direction 


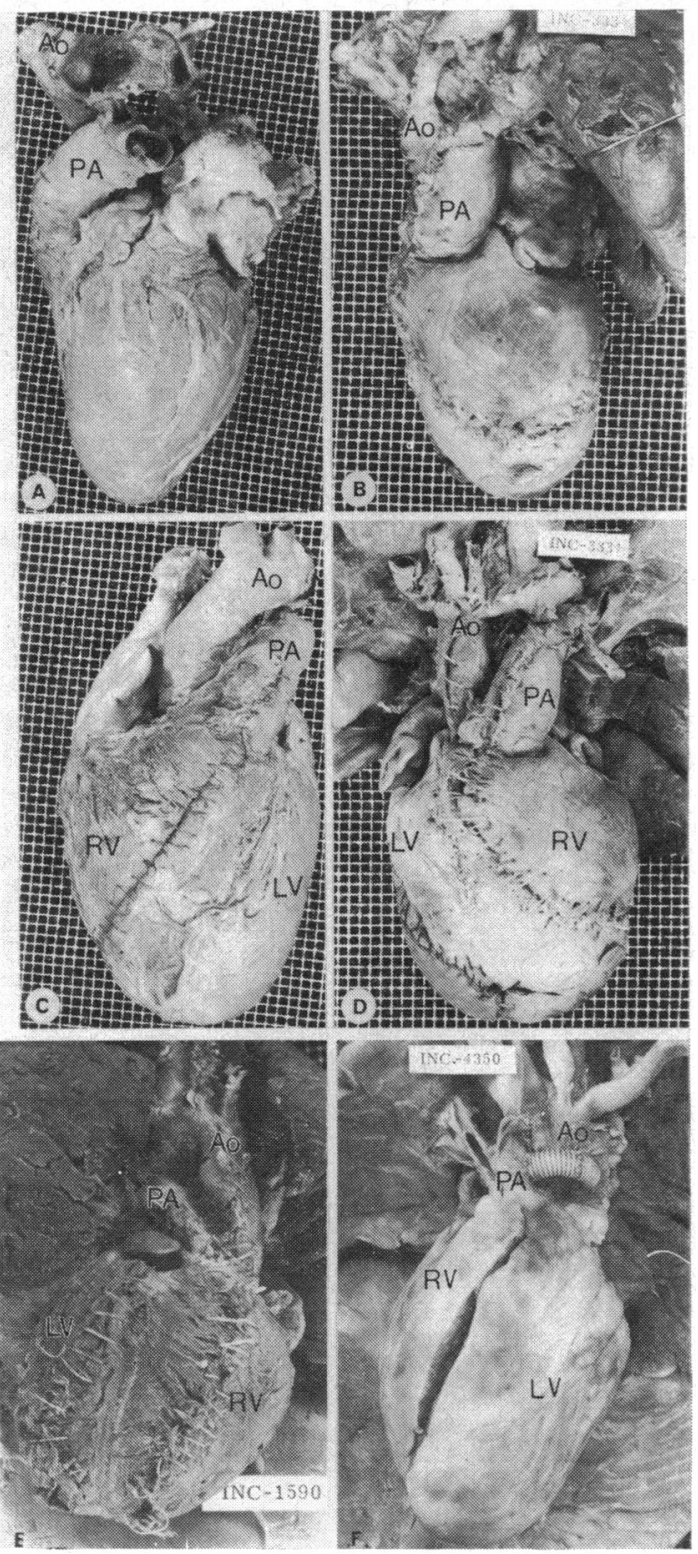

and orientation; the same is true of the aorta and its infundibulum (de la Cruz and Nadal-Ginard, 1972) (Compare B, D with C, E in Fig. 6 and C, E with $\mathrm{D}, \mathrm{F}$ in Fig. 8).

The clinical diagnosis is made fundamentally by means of the radiological study of the position of cardiac catheters in the lateral and anteroposterior projections and with biplane angiocardiography. In the lateral projection the anterior position of the pulmonary artery and its infundibulum with respect to the aorta is confirmed (crossed great arteries) (Fig.
FIG. 7 External view of anatomical specimens of concordant and discordant crossed great arteries. Angiographic studies of these specimens are shown in Fig. 8. (A) Lateral view of case of concordant crossed great arteries and $(B)$ of discordant crossed great arteries. Notice that in both pulmonary artery trunk is anterior with respect to ascending portion of aortic arch. (C) Concordant crossed great arteries with pulmonary artery trunk directed from right to left. (D) Discordant crossed great arteries with pulmonary artery trunk directed from right to left. (E) Concordant crossed great arteries with pulmonary artery trunk directed from left to right. (F) Discordant crossed great arteries with pulmonary artery trunk directed from left to right.

Key to abbreviations: Ao, aorta; $P A$, pulmonary artery; $R V$, right ventricle; $L V$, left ventricle.

$8 \mathrm{~A})$. With the anteroposterior projection the fact can be established that the pulmonary artery and its infundibulum follow the same spatial direction (crossed great arteries with arterioventricular concordance) (Fig. 8C and E). Because the pulmonary artery emerges from the anterior infundibulum which corresponds to the anatomical right ventricle, the relation of the pulmonary artery trunk and its infundibulum allows identification of the spatial position of the anatomically right ventricle. Thus, when the pulmonary artery and its infundibulum are directed from right to left it means that the anatomically right ventricle is placed on the right side (Fig. 6B and $8 \mathrm{C}$ ), whereas if the pulmonary artery and its infundibulum are directed from left to right, this indicates that the anatomically right ventricle is placed on the left side (de la Cruz and Nadal-Ginard, 1972) (Fig. 6D and 8E).

2. Discordant crossed great arteries (de la Cruz et al., 1974) (Fig. 6A, C, E, 7B, D, F and 8B, $D, F)$. Crossed great arteries with arterioventricular discordance (discordant crossed great arteries) have, therefore, the general features of crossed great arteries, i.e. the pulmonary artery is ventral to the aorta and it arises from the anterior infundibulum (anatomically right ventricle) (Fig. 6A, C, E, 7B, D, $\mathrm{F}$ and $8 \mathrm{~B}, \mathrm{D}, \mathrm{F})$. The distinctive feature in this group is that the pulmonary artery and its infundibulum (anterior infundibulum) do not have the same spatial direction, the same is true of the aorta and its infundibulum. (Compare C, E with B, D in Fig. 6 and $D, F$ with $C, E$ in Fig. 8.)

This group is diagnosed with the same laboratory techniques as the previous group, first confirming the diagnosis of crossed great arteries in the lateral angiocardiogram, i.e. anterior position of the pulmo- 
FIG. 8 Angiocardiographic postmortem study of specimens of concordant and discordant crossed great arteries. (A) Lateral view of concordant crossed great arteries and $(B)$ of discordant crossed great arteries. Both show pulmonary artery trunk and infundibulum anteriorly placed with respect to aorta and its infundibulum which is a general characteristic of crossed great arteries. (C) Frontal view of concordant crossed great arteries and (D) discordant crossed great arteries. Observe (C) that the pulmonary artery trunk, which is anterior, is directed from right to left and originates from an anterior infundibulum located on right, which indicates that anatomically right ventricle is placed on right, while in (D) the pulmonary artery trunk also directed from right to left but originating from an anterior infundibulum located to left, indicates that the anatomical right ventricle is placed on left side. (E) Frontal view of concordant crossed great arteries and $(F)$ discordant crossed great arteries. Observe in (E) that the anteriorly placed pulmonary artery trunk directed from left to right arising from an anterior infundibulum placed on left side, indicates that the anatomical right ventricle is placed on the left, while in $(F)$, the pulmonary artery trunk is also directed from left to right but arising from an anterior infundibulum placed on the right side indicates that the anatomically right ventricle is placed on the right side. Dotted arrow indicates direction of infundibulum of the anatomically right ventricle. Full arrow indicates direction of pulmonary artery.

Key to abbreviations: Ao, aorta; $P A$, pulmonary artery; $R V$, right ventricle; $L V$, left ventricle.

nary artery and its infundibulum with respect to the aorta (Fig. 8B) and then analysing the frontal or anteroposterior projection in order to establish the fact that the pulmonary artery trunk and its infundibulum do not follow the same spatial direction (crossed great arteries with arterioventricular discordance) (Fig. 8D and F). Because the pulmonary artery arises from the anterior infundibulum which corresponds to the anatomically right ventricle, the relation between the trunk of the pulmonary artery and its infundibulum allows the identification of the spatial position of the anatomically right ventricle. If, for instance, the pulmonary artery is directed from right to left and it emerges from a left-sided infundibulum, it indicates that the anatomically right ventricle is placed on the left side (Fig. 6C and $8 \mathrm{D}$ ), while if the pulmonary artery is directed from left to right arising from a right-sided infundibulum, the anatomically right ventricle must be placed on the right side (Fig. $6 \mathrm{E}$ and $8 \mathrm{~F}$ ).

There are two anatomical varieties within this
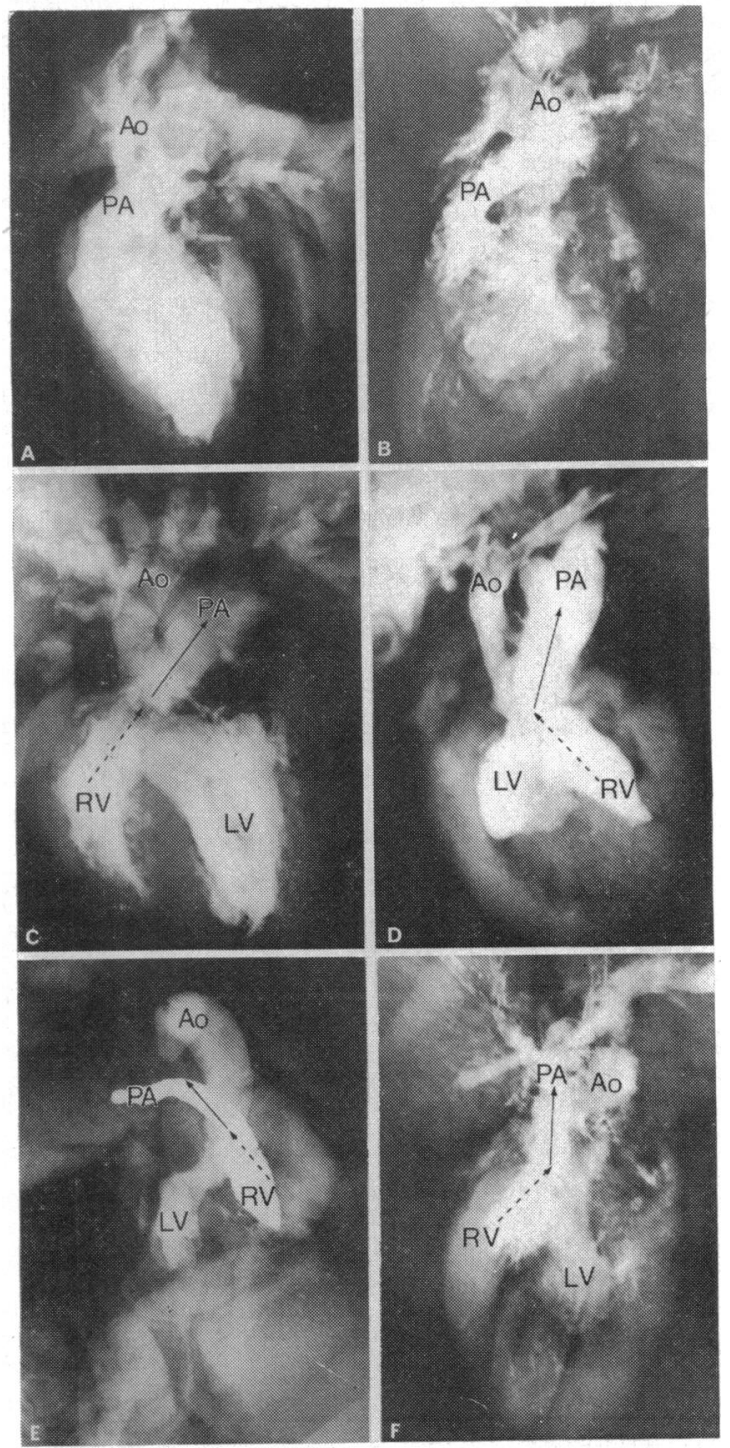

group depending on the direction of the pulmonary artery trunk and its infundibulum (de la Cruz et al., 1974). The anatomical image of the variety with pulmonary artery directed from right to left emerging from a left-sided infundibulum which in turn is directed from left to right in a caudo-cranial sense is characterized by the fact that the pulmonary artery trunk and its infundibulum form a curve convex to the right and concave to the left. This curve is ventrally placed with respect to the curve formed by the aorta and its infundibulum, which in turn is concave to the right and convex to the left 
(Fig. 6C and 8D). The entire image is that of an $\mathrm{X}$ whose two left limbs formed by the pulmonary artery trunk and the infundibulum of the anatomically right ventricle placed on the left side overlap the two right limbs of the $\mathrm{X}$ at the level of the valvular floors. The right limbs in turn are formed by the ascending portion of the aortic arch and the infundibulum of the anatomically left ventricle placed on the right side (Fig. 6C, 7D, and 8D). The reciprocal relation of the valvular floors of the great arteries is that observed when the pulmonary artery is directed from right to left in cases of concordant crossed great arteries (de la Cruz et al., 1974) (Compare $C$ with $B$ in Fig. 6).

The variety with the pulmonary artery directed from left to right emerging from an infundibulum placed on the right side, which in turn is directed from right to left in a caudo-cranial sense is characterized by the pulmonary artery trunk and its infundibulum form a curve concave to the right and convex to the left. This curve is placed ventrally with respect to the curve formed by the ascending portion of the aortic arch and its infundibulum which is concave to the left and convex to the right (Fig. 6E and $8 \mathrm{~F}$ ). In this variety the right limbs of the $\mathrm{X}$, formed by the pulmonary artery trunk and the infundibulum of the anatomically right ventricle placed on the right side also overlap the two left limbs of the $X$ at the level of the valvular planes. Those limbs are constituted by the ascending portion of the aortic arch and the infundibulum of the anatomically left ventricle placed on the left (Fig. $6 \mathrm{E}, 7 \mathrm{~F}$, and $8 \mathrm{~F}$ ). The reciprocal relation of the valvular floors of the aorta and the pulmonary artery is that which corresponds to that seen when the pulmonary artery is directed from left to right in concordant crossed great arteries (de la Cruz et al., 1974) (Compare E with D in Fig. 6).

\section{B. Transposition of the great arteries}

The truncoconal morphology of transposition of the great arteries is characterized essentially by the fact that the ascending portion of the aortic arch always has a ventral position with respect to the pulmonary artery (Fig. 3, 4 and 5) since the aorta emerges from the anterior infundibulum (de la Cruz and da Rocha, 1956) (anatomically right ventricle). This entity includes two groups: one with arterioventricular concordance (Fig. 3A, B, D, 4A, C, E and 5A, C, E) and one with arterioventricular discordance (Fig. $3 A, C, E, 4 B, D, F$ and $5 B, D, F)$.

1. Concordant transposition of the great arteries (De la Cruz et al., 1974) (Fig. 3A, B, D, $4 A, C, E$ and $5 A, C, E)$. Within the group of trans- position of the great arteries the concordant form occurs most often. This type has the general features of transposition of the great arteries, i.e. the ascending portion of the aortic arch is ventrally placed with respect to the trunk of the pulmonary artery and it arised from the anterior infundibulum (anatomically right ventricle) (Fig. $3 \mathrm{~A}, \mathrm{~B}, \mathrm{D}, 4 \mathrm{~A}, \mathrm{C}, \mathrm{E}$ and $5 \mathrm{~A}, \mathrm{C}, \mathrm{E})$. The distinctive feature in this entity is that the ascending portion of the aortic arch and its infundibulum (anterior unfundibulum) are placed on the same side in the frontal plane and parallel to the pulmonary artery trunk and its infundibulum (de la Cruz and Nadal-Ginard, 1972) (Compare B, D with C, E in Fig. 3 and C, E with D, F in Fig. 5).

The clinical diagnosis is made with the radiological study of the position of cardiac catheters in the lateral and anteroposterior projections and by the use of biplane angiocardiography. The lateral projection confirms the anterior position of the aorta and its infundibulum with respect to the pulmonary artery (transposition of the great arteries) (Fig. 5A); with the anteroposterior projection the fact is established that the aorta and its infundibulum are placed on the same side in the frontal plane and parallel to the pulmonary artery and its infundibulum (transposition of the great arteries with arterioventricular concordance) (Fig. 5C and E). Because of the fact that the aorta emerges from the anterior infundibulum which corresponds to the anatomically right ventricle, the relation of the ascending portion of the aortic arch and its infundibulum allows the identification of the spatial position of the anatomically right ventricle. Thus, when the aorta and its infundibulum are placed to the right of the pulmonary artery and its infundibulum it indicates that the anatomically right ventricle is placed on the right (anterior infundibulum to the right) (Fig. 3B and $5 \mathrm{C}$ ), whereas if the aorta and its infundibulum are placed to the left of the pulmonary artery and its infundibulum, it indicates that the anatomically right ventricle is placed on the left (anterior infundibulum on the left side) (de la Cruz and Nadal-Ginard, 1972) (Fig. 3D and 5E).

2. Discordant transposition of the great arteries (de la Cruz et al., 1974) (Fig. 3A, C, E, $4 B, D, F$ and 5B, D, F). Transpositions of the great arteries with arterioventricular discordance present the general features of transposition of the great arteries, i.e. the ascending portion of the aortic arch is anteriorly placed with respect to the pulmonary artery trunk and it arises from the anterior infundibulum (anatomically right ventricle) (Fig. 3A, C, E, 4B, D, $\mathrm{F}$ and $5 \mathrm{~B}, \mathrm{D}, \mathrm{F})$. The feature peculiar to this group is the fact that the ascending portion of the aorta emerges from the anterior infundibulum placed on the 
opposite side in the frontal plane (compare $\mathrm{C}$ and $\mathrm{E}$ with $B$ and $D$ in Fig. 3 and $D$ and $F$ with $C$ and $E$ in Fig. 5). In this group the diagnosis is made with the same techniques described above, first corroborating the diagnosis of transposition of the great arteries by the anterior position of the aorta and its infundibulum with respect to the pulmonary artery in the lateral projection (Fig. 5B) and then determining in the anteroposterior projection that the ascending portion of the aortic arch arises from an infundibulum placed on the opposite side in the frontal plane (transposition of the great arteries with arterioventricular discordance) (Fig. 5D and F). Owing to the fact that the aorta emerged from the anterior infundibulum which corresponds to the anatomically right ventricle, the relation of the ascending portion of the aortic arch and its infundibulum enables identification of the spatial position of the anatomically right ventricle. Thus, if the aorta is placed on the right side of the pulmonary artery and it emerges from an infundibulum placed on the left side, it indicates that the anatomically right ventricle is placed on the left side (Fig. 3C and 5D), whereas if the aorta is placed on the left side of the pulmonary artery and it arises from an infundibulum located on the right side, it indicates that the anatomically right ventricle is placed on the right side (Fig. 3E and 5F).

This group comprises two anatomical varieties which depend on the position of the aorta and its infundibulum (de la Cruz et al., 1974). The anatomical variety with a right-sided aorta is characterized because the aorta placed on the right of the pulmonary artery is continuous with the anterior infundibulum placed on the left side which is directed from left to right in a caudo-cranial sense (anatomically right ventricle placed on the left) (Fig. 3C and 5D), while the pulmonary artery is placed behind and to the left of the aorta, and it emerges from a posterior infundibulum placed on the right side and directed from right to left in a caudo-cranial sense (anatomically left ventricle placed on the right side) (Fig. $3 \mathrm{C}$ and 5D). The reciprocal relation of the valvular planes of the great arteries is that seen when the aorta is placed on the right side of the pulmonary artery in transposition of the great arteries (de la Cruz et al., 1974) (Compare $C$ with $B$ in Fig. 3).

The anatomical variety with the aorta placed on the left side of the pulmonary artery is characterized by the aorta being continuous with the anterior infundibulum which is placed on the right side and directed from right to left in a caudocranial sense (anatomically right ventricle placed on the right side) (Fig. $3 \mathrm{E}$ and $5 \mathrm{~F}$ ), whereas the pulmonary artery is placed behind and to the right of the aorta, and it emerges from the posterior infundibulum which is placed on the left side and directed from left to right in a caudo-cranial sense (anatomically left ventricle placed on the left) (Fig. 3E and 5F). The reciprocal relation of the valvular planes of the great arteries is that seen in transposition of the great arteries with the aorta placed on the left side of the pulmonary artery (de la Cruz et al., 1974) (compare E with D in Fig. 3).

The rules to locate the ventricle by the analysis of the truncoconal morphologies in arterioventricular discordances are valid, as in arterioventricular concordances (de la Cruz et al., 1974), whether the two great arteries emerge from the anatomically right ventricle or one artery arises from one ventricle and the other overrides or else when both arteries arise from the anatomically left ventricle.

In a previous paper one of us (de la Cruz et al., 1974) had maintained that the ventricular cavities could not be located spatially in arterioventricular discordances with crossed great arteries or with transposition of the great arteries, following the rules established for the identification of these cavities in arterioventricular concordances. This fact remains true. However, the ventricular cavities can be identified in arterioventricular discordances applying the specific rules established in this paper for the diagnosis of these malformations.

The rules for the spatial location of the ventricles in transposition of the great arteries with arterioventricular concordance or discordance, are not applicable to the 'anatomically corrected transposition' because this malformation, by our definition, is not a transposition of the great arteries.

Van Praagh et al. (1971) also conclude that anatomically corrected transposition must be excluded from the group of transposition of the great arteries, 'because transposition in fact is not present', and he designates it as 'anatomically corrected malposition'. In a previous paper we indicated (de la Cruz et al., 1974) that anatomically corrected transposition is a partial distorsion of the great arteries with arterioventricular discordance, for which reason the rules for spatial identification of the ventricles in cases of crossed great arteries with arterioventricular concordance or discordance are not applicable either.

\section{Diagnosis of visceral situs}

Arterioventricular discordances, as well as arterioventricular concordances may occur in situs solitus or in situs inversus. The diagnosis of the visceral situs is established identifying the spatial position of the hepato-cavo-atrial complex, formed by the 


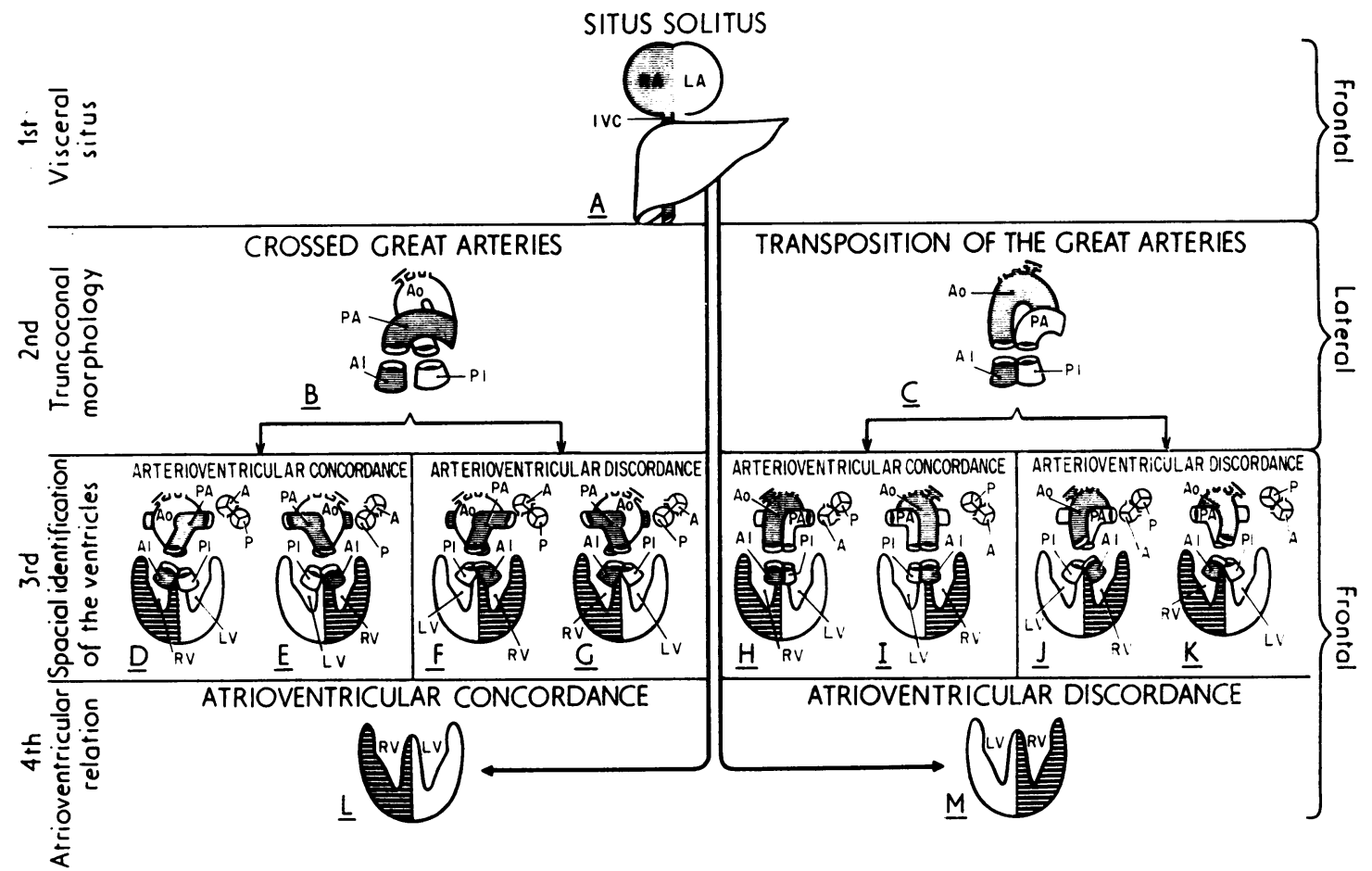

FIG. 9 Representative diagram depicting sequence that should be followed in order to establish differential diagnosis between crossed great arteries and transposition of great arteries and also of different varieties of these two entities. ( $A$ ) Characteristics of situs solitus. ( $B$ and $C$ ) Differential signs between crossed great arteries and transposition of great arteries. ( $D, E, F, G$, $H, I, \mathcal{F}$, and $K$ ) Characteristics of arterioventricular concordances and discordances in crossed great arteries and in transposition of great arteries and spatial location of ventricles. Relation expressed by arrow between ( $L$ and $M$ ) with $(A)$ allows specification of presence of atrioventricular concordance or discordance.

Key to abbreviations: Ao, aorta; $P A$, pulmonary artery; $A I$, anterior infundibulum; $P I$, posterior infundibulum; $R V$, right ventricle; $L V$, left ventricle; $A$, aortic sigmoid valve cusps; $P$, pulmonary sigmoid valve cusps; $R A$, right atrium; $L A$, left atrium; IVC, inferior vena cava.

large lobe of the liver, the suprahepatic portion of the inferior vena cava, and the anatomically right atrium independently of the position of the other segments of the heart and the rest of the viscera (de la Cruz and Nadal-Ginard, 1972). The identification of the anatomically right atrium is made by identifying radiologically the position of the catheter in the suprahepatic segment of the inferior vena cava or with angiocardiography.

The diagnosis of situs solitus is made when the hepato-cavo-atrial complex is placed on the right side and that of situs inversus when this anatomical complex is placed on the left side.

The cardiac apex may have three different directions in each situs. In situs solitus the apex is directed to the left (normally placed heart), medial apex (mesocardia), and apex to the right (dextro- version). In situs inversus there may be a rightsided apex (mirror-image dextrocardia), a medial apex (mesocardia), or an apex directed to the left (laevoversion) (Anselmi et al., 1972).

\section{Diagnosis of atrioventricular relation}

Arterioventricular discordances, like arterioventricular concordances, may present with atrioventricular concordance or atrioventricular discordance (de la Cruz et al., 1974).

Atrioventricular concordances are characterized by the anatomically right atrium and the anatomically right ventricle being placed in the same side in space, independently of their position within the chest. In situs solitus both are on the right and in situs inversus both are on the left. Atrioventricular 
discordances are characterized by the fact that the anatomically right atrium and the anatomically left ventricle are placed spatially on the same side independently of their position within the chest. In situs solitus both are placed on the right and in situs inversus both are placed on the left side.

The diagnosis of atrioventricular concordance or discordance is made following this sequence: 1) The situs is identified by a radiological study in order to locate the hepato-cavo-atrial anatomical complex in space. 2) The truncoconal morphology is identified. 3) The diagnosis of arterioventricular discordance or concordance is made, which in turn permits the spatial identification of the ventricles in these entities. 4) The spatial relation is established between the atria and the ventricles (Fig. 9).

\section{References}

Anselmi, G., Muñoz, S., Blanco, P., Machado, I., and de la Cruz, M. V. (1972). Systematization and clinical study of dextroversion, mirror-image dextrocardia, and laevoversion. British Heart fournal, 34, 1085.

Danielson, G. K., Ritter, D. G., Coleman, H. N., and DuShane, J. W. (1972). Successful repair of double-outlet right ventricle with transposition of the great arteries (aorta anterior and to the left), pulmonary stenosis, and subaortic ventricular septal defect. Fournal of Thoracic and Cardiovascular Surgery, 63, 741.

de la Cruz, M. V., Amoedo, M., Rivera, F., and Attie, F. (1974). Arterioventricular relations and their classification. Two specimens of arterioventricular discordance and review of published reports. British Heart fournal, 36, 539.

de la Cruz, M. V., and da Rocha, J. P. (1956). An ontogenetic theory for the explanation of congenital malformations involving the truncus and conus. American Heart fournal, $51,782$.

de la Cruz, M. V., Muñoz-Armas, S., and MuñozCastellanos, L. (1972). Development of the Chick Heart. Johns Hopkins University Press, Baltimore and London.

de la Cruz, M. V., and Nadal-Ginard, B. (1972). Rules for the diagnosis of visceral situs, truncoconal morphologies, and ventricular inversions. American Heart fournal, 84, 19.

de Vries, P. A., and Saunders, J. B. de C. M. (1962). Development of the ventricles and spiral outflow tract in the human heart. A contribution to the development of the human heart from age group IX to age group XV. Contributions to Embryology, 37, 87.

Gessner, I. H., and Van Mier(p, L. H. S. (1970). Experimental production of cardiac defects: the spectrum of dextroposition of the aorta. American fournal of Cardio$\log y, 25,272$.
Goor, D. A., Dische, R., and Lillehei, C. W. (1972). The conotruncus. I. Its normal inversion and conus absorption. Circulation, 46, 375.

Kirklin, J. W., Pacifico, A. D., Bargeron, L. M., and Soto, B. (1973). Cardiac repair in anatomically corrected malposition of the great arteries. Circulation, 48, 153.

Kramer, T. C. (1942). The partitioning of the truncus and conus and the formation of the membranous portion of the interventricular septum in the human heart. American Fournal of Anatomy, 71, 343.

Netter, F. H., and Van Mierop, L. H. S. (1969). Embryology. In CIBA Collection of Medical Illustrations, Vol. 5, Section 3. Ed. by F. H. Netter. Ciba Pharmaceutical Co., Summit, New Jersey.

Raghib, G., Anderson, R. C., and Edwards; J. E. (1966). Isolated bulbar inversion in corrected transposition. American fournal of Cardiology, 17, 407.

Shaffer, A. B., Lopez, J. F., Kline, I. K., and Lev, M. (1967). Truncal inversion with biventricular pulmonary trunk and aorta from right ventricle (variant of Taussing-Bing complex). Circulation, 36, 783.

Streeter, G. L. (1945). Developmental horizons in human embryos. Description of age group XIII, embryos about 4 or 5 millimeters long, and age group XIV, period of indentation of the lens vesicle. Contributions to Embryology, 31, 27.

Van Mierop, L. H. S. (1974). Anatomy and embryology of the right ventricle. In The Heart, p. 1. Ed. by J. E. Edwards, M. Lev, and M. R. Abell. Williams and Wilkins, Baltimore.

Van Mierop, L. H. S., Alley, R. D., Kausel, H. W., and Stranahan, A. (1962). The anatomy and embryology of endocardial cushion defects. Fournal of Thoracic and Cardioziascular Surgery, 43, 71.

Van Praagh, R. (1973). Conotruncal malformations. In Heart Disease in Infancy: Diagnosis and Surgical Treatment, p. 141. Ed. by B. G. Barratt-Boyes, J. M. Neutze, and E. A. Harris. Churchill Livingstone, Edinburgh.

Van Praagh, R., Durnin, R. E., Jockin, H., Wagner, H. R., Korns, M., Garabedian, H., Ando, M., and Calder, A. L. (1975). Anatomically corrected malposition of the great arteries (S.D.L.). Circulation, 51, 20.

Van Praagh, R., Pérez-Treviño, C., López-Cuellar, M., Baker, F. W., Zuberbuhler, J. R., Quero, M., Pérez, V. M., Moreno, F., and Van Praagh, S. (1971). Transposition of the great arteries with posterior aorta, anterior pulmonary artery, subpulmonary conus and fibrous continuity between aortic and atrioventricular valves. American fournal of Cardiology, 28, 621.

Van Praagh, R., and Van Praagh, S. (1966). Isolated ventricular inversion. A consideration of the morphogenesis, definition and diagnosis of nontransposed and transposed great arteries. American fournal of Cardiology, 17, 395.

Requests for reprints to Dr. M. V. de la Cruz, Department of Embryology, Instituto Nacional de Cardiología, Av. Cuauhtemoc No. 300, Mexico 7 D.F., Mexico. 